Studia Anglica Posnaniensia 45/1, 2009

(C) School of English, Adam Mickiewicz University, Poznań, Poland

doi: 10.2478/v10121-009-0001-x

\title{
THE GRAMMATICAL STATUS OF THE SAME
}

\author{
R. M. W. DIXON
}

James Cook University, Townsville

\begin{abstract}
The same, consisting of two words (or of clinic-plus-word), functions as a single grammatical item. Basically, it belongs to the determiner slot in phrase structure (together with articles, demonstratives and possessors). Like demonstratives, it may function as a substitution anaphor. But the same also shares some properties with adjectives - it can make up a complete copula complement, it may be the first element of a reduced relative clause, it may be followed by a preposition plus NP, and it has limited function as an adverb.
\end{abstract}

\section{Introduction}

Why is it that same must be accompanied by the definite article the when used as a copula complement, whereas different never is. Compare:

1) Today's message is [the same] as yesterday's message.

2) Today's message is [different] from yesterday's message.

When used as modifier within an NP, same must again be preceded by the:

3) The same message came today.

Different is most frequently preceded, within an NP, by indefinite article $a$ :

4) A different message came today.

However, it is possible to use the with different. Suppose that every day for 
three months the same message had appeared on your computer screen. Then one day a different message is found there. The following day, yesterday's message appears again. You can say:

5) The different message came again today.

Or you can even include both the same and different, in this order:

6) The same different message came again today.

One can get two adjectives together in an NP - for example, the little white house, and a nasty wet day - but not, as a rule, two from the same semantic type. Does the fact that the same and different may co-occur, as in (6), suggest that the same is not really an adjective at all, but instead some other kind of modifier within an NP?

To respond to this question, we shall first survey the set of adjectives which require two arguments, then examine the difference of meaning between the same and identical, before studying how the same slots into the structure of an NP and examining its grammatical properties. ${ }^{1}$

2. Adjectives which require two arguments

Most adjectives - in English and in every other language - simply modify a noun. But there is a small set which indicate a relation between two arguments. Using $\mathrm{X}$ and $\mathrm{Y}$ for the arguments, one can say either:

\section{7) $\mathrm{X}$ be ADJECTIVE PREPOSITION Y}

or

\section{8) $\mathrm{X}$ and $\mathrm{Y}$ be ADJECTIVE}

For example, different (from) may occur in either of:

9) Today's message is different from yesterday's message.

10) Today's message and yesterday's message are different.

The constructions for equal (to) are illustrated by:

11) In a right-angled triangle, the square on the hypotenuse is equal to the

1 Huddleston (2002: 1137-40) provides an excellent discussion of same within "comparative constructions", a quite different matter from that investigated here. 
sum of the squares on the other two sides.

12) In a right-angled triangle, the square on the hypotenuse and the sum of the squares on the other two sides are equal.

Adjectives relating to two arguments differ concerning which preposition(s) they require for occurrence in framework (7). The set includes:

13) identical (to/with) different (from/than/to)

similar (to) dissimilar (to/from)

equal (to/with) separate (from)

related (to) independent (of)

comparable (to/with) consistent (with)

simultaneous (with) concurrent (with)

At first glance, the same (as) appears to belong in this set of adjectives. For instance, one can say either of:

14) Today's message is the same as yesterday's message.

15) Today's message and yesterday's message are the same.

In this respect, the same (as) does pattern like adjectives different and identical. Once we look further, however, differences emerge. But before delving further into grammar, we can compare the meanings of the same (as) and identical (to/with).

3. Meaning contrast between the same and identical

The difference between the canonical meanings of the same (as) and identical (to) is perfectly straightforward:

- If " $\mathrm{X}$ and $\mathrm{Y}$ are the same", then $\mathrm{X}=\mathrm{Y}$. That is, there is only one entity involved.

- If " $\mathrm{X}$ and $\mathrm{Y}$ are identical", then there are two entities (that is, it is not the case that $\mathrm{X}=\mathrm{Y}$ ). The two entities are very similar in certain respects so that it can be difficult to tell them apart.

A grammarian of English will say that determiners and possessors go into the same slot in NP structure. That is, determiners go into slot (c) and possessors also go into slot (c) - see $\S 4$. One cannot say that determiners and possessors go into identical slots since only one slot is involved, not two.

"Identical twins" are not one person but two people who it is difficult to tell 
apart. This is why we use identical here rather than the same. In contrast, the "morning star" and the "evening star" are not two identical stars but one and the same star (the planet Venus) which is accorded different names depending on the time of day at which it is observed.

The canonical meanings of the same and identical are thus quite clear. There is - as is always the case - extension of meaning in everyday usage, such that in some circumstances the same and identical may be used interchangeably. ${ }^{2}$ For example, if someone is comparing his stamp collection with that of a friend, he may exclaim (with pointing):

16) This stamp of mine is the same as that stamp of yours.

Strictly speaking, the collector should have used is identical to rather than is the same as. But since two stamps are being considered (rather than just one), the meaning is clear. Quite often the same is used as an abbreviation for the same in [some] respect. For instance, if one hears The houses in that street are all the same, it would probably be inferred that they are of the same design. The Germanic term same is far more frequent ${ }^{3}$ than the Romance borrowing identical and, related to this, it has wide extensions of meaning.

However, there are many situations in which only one of the same and identical may be employed, as illustrated by the examples given a little earlier.

Identical is like different in that it may be preceded by definite article the or indefinite article $a$, whereas same may not occur with $a$.

Just as the same may be used with different, so it may be used before identical. For example:

17) The same (set of) identical twins came to Tom's party as to Laura's party.

It is clear that identical belongs to the set of double-argument adjectives illustrated in (13). We will see that the same has a different grammatical status; that is, it is not an adjective. The same can usefully be referred to as an "identifier".

2 Dictionaries are typically lax in distinguishing meanings of semantically similar words. The second edition of the OED (Simpson - Weiner 1989), for instance, gives as definition of identical "the same, the very same: said of one thing (or set of things) viewed at different times or in different relations" and for same it says "the ordinary adjectival and pronominal designation of identity".

The Cobuild dictionary aims to define less frequent words in terms of more frequent ones. For identical it states "things that are identical are exactly the same" (Sinclair 2001: 774).

3 The Cobuild Dictionary (Sinclair 2001: xiii-xv, 774, 1373) lists same in frequency Band 5, while identical is in Band 2. 


\section{Pre-head elements in NP structure}

The following is a summary of the elements which may precede the head of an NP in English (this is taken from Dixon 2005: 26):

a) an adverb which modifies a complete NP, e.g. even, simply, really; or what, as in what a scandal, what the devil, or such as in such a nice boy, such delicious oysters;

b) a predeterminer, e.g. all (of), some (of), both (of), one-quarter (of);

c) a determiner, which can be

i) an article (the, a),

ii) a demonstrative (e.g. this, those), or

iii) a possessor word or NP (my, John's, the old man's);

d) a superlative (tallest, most beautiful), a comparative (taller, more beautiful); or an ordering word (next, last) and/or a cardinal number (three) or a quantifier (many, few);

e) an ordinal number, e.g. fourth;

f) one or more adjectival modifiers; an adjective here may be modified by an adverb (such as simply, really or very);

g) a modifier describing composition (wooden, vegetable, electrical);

h) a modifier describing origin or style (British, outside in outside toilet);

i) a modifier describing purpose/beneficiary (e.g. rabbit in rabbit food, medical in medical building).

5. Which structural slot is appropriate for the same?

The appropriate slot for identifier the same is (c) - alongside articles, demonstratives and possessors - whereas different, identical and other items from (13) are in slot (f). One says the same (c) two (d) messages but the (c) two (d) different (f) messages. ${ }^{4}$ Other exemplars of ordering are:

18) [The same three different messages] appeared on the screen today as

c d f

yesterday.

4 It is sometimes possible to permute the order of elements in an NP, for semantic and/or pragamatic reasons, but this always receives special stress marking. Thus, if one were talking about sets each consisting of two messages, one could conceivably say the different 'two messages. This non-standard ordering would be marked by placing special stress on two. 
19) She brought along with her [the same most idiotic third husband as last

c d e r year].

Note that different (slot f) can be preceded by a possessor (slot c):

20) Your different approach to the problem is most refreshing.

In contrast, the same may not co-occur with a possessor; one cannot say *your the same or *the your same or *the same your. This is consistent with the same and possessors both belonging to slot (c), from which only one item may be selected. (All that is possible in order to combine the same and a possessor is a circumlocution, along the lines of The same old approach, which you keep putting forward, is not at all helpful.)

Although same is normally preceded by the, it can take a demonstrative instead - this, that, these or those. For example:

21) These same miners are on strike again.

22) He was wearing that same tie as at the previous interview.

We can now interpolate set (iii), into slot (c) of NP structure:

iii) an identifier (the same or this/that/these/those same)

In the interests of concision, for the remainder of this paper the same will be used as an abbreviation covering all of the/this/that/these/those same.

6. Special properties of the identifier the same

Grammars are never absolutely tidy. We have analysed the same as an identifier in slot (c-iii) of NP structure. Nevertheless, the same does share properties with the set of two-argument adjectives from slot (f). For example, each of them can be followed by post-head PREPOSITION-plus-NP within the NP for which they are a pre-head modifier:

23) [The same message [as yesterday's]] appeared on the screen today.

24) [A similar message [to yesterday's]] appeared on the screen today.

25) [A different message [from yesterday's]] appeared on the screen today.

An NP head may be followed by the same or different which are, in fact, the first elements of a reduced relative clause. For example: 
26) [Two messages [(which are) the same as yesterday's $\left.\left.]_{\mathrm{RC}}\right]\right]$ appeared on the screen.

27) [Two messages $\left.\left.[(\text { which are }) \text { different from yesterday's }]_{\mathrm{RC}}\right]\right]$ appeared on the screen.

This is a property which the same and different share with most adjectives. For instance:

28) [A new message $\left.[\text { (which is) impossible to understand }]_{\mathrm{RC}}\right]$ just arrived.

Many adjectives form an adverb by adding -ly (for details see Dixon 2005: 381-385). This applies to the double-argument adjectives in (13). One can say John made his decision independently (of Mary) and Tom behaved similarly (to Kate). It is interesting that the same may function as an adverb (without any derivational suffix being added). Compare (examples from Huddleston 2002: 1138):

29) She treats them all differently.

30) She treats them all identically.

31) She treats them all the same.

Some speakers would prefer to say He treats them all in the same way, rather than (31). However, constructions such as (31) are fairly well attested although they may be of recent origin, ${ }^{5}$ created by analogy with sentences like (29-30).

Having pointed out several respects in which the same behaves like adjectives, we can mention one way in which it shares a grammatical property with demonstratives. Substitution anaphora (Dixon 2003: 83-85, 111-112) may involve a demonstrative:

32) John has ordered coffee and I'll have that too.

The same may also be used as a substitution anaphor:

33) John has ordered coffee and I'll have the same.

Different and identical (and other double-argument adjectives) lack this property.

We can now turn to consideration of the same as copula complement, as illustrated at the beginning of this paper by sentence (1).

5 This is based on examination of the considerable corpus in the $O E D$ entry for same. 
7. The same as copula complement

A copula complement may consist of an NP or of an adjective. A further way in which the same patterns with adjectives is that it may make up a copula complement on its own, as in (1) and:

14) Today's message is [the same] as yesterday's message.

15) Today's message and yesterday's message are [the same].

The interesting point is that, even when functioning as copula complement, same must still be accompanied by the (a demonstrative would not be appropriate in this context).

Instead of (14) and (15), one could say:

14') Today's message is [the same message] as yesterday's (message).

$\left.15^{\prime}\right)$ Today's message and yesterday's message are [the same message].

It could be suggested that $\left(14^{\prime}\right)$ and $\left(15^{\prime}\right)$ are the underlying structures for (14) and (15). In order not to state the word message three times it is omitted from the end of (15). And in (14) it is stated after yesterday instead of after the same (although it is understood to be in underlying structure after the same).

But, whether or not this analysis is accepted, it is a fact that this is another way in which the same behaves like an adjective, although in terms of position it is a determiner (slot c) within NP structure.

Once again, same requires a preceding the. This applies to same in all contexts in which it occurs. Examples from the $O E D$ show that same has required a preceding the from the earliest stages of the language. However, we could not regard the same as a single syntagmatic unit since very can intrude between definite article and same - the very same message. Maybe the association between the and same has some similarities to that between the two elements of a verb such as bring in. The phrasal verb bring in is a single lexical item but its components need not occur contiguously - alongside The farmer brought in the cows we get The farmer brought the cows in.

\section{Summary}

We have been discussing the "identifier" the same and this/that/these/those same which involve same preceded by the article the - from slot (c-i) in NP structure - or a demonstrative - from slot (c-ii). (We use the same as abbreviation for these five forms.) 
- As regards position within an NP, the same belongs in slot (c). It is mutually exclusive with possessors - also in slot (c) - and may be preceded by items from slots (a-b) and followed by items from slots from (d) on.

- The same may function as substitution anaphor, like demonstratives which also belong to slot (c).

- The same shares an important property with double-argument adjectives (from slot $\mathrm{f}$ ) - it may be followed by preposition plus NP.

- Like adjectives (in slot $\mathrm{f}$ ) the same may be the first element of a reduced relative clause.

- Like many adjectives, the same has limited function as an adverb (and retains its form for this function, not taking derivational suffix -ly as adjectives do).

- $\quad$ Like adjectives, the same can make up a complete copula complement. We see that the identifier item the same has unique form, including definite article the (or, in some contexts, a demonstrative). It functions in some ways like a determiner and in other like an double-argument adjective.

\section{REFERENCES}

Dixon, R. M. W.

2003 "Demonstratives: a cross-linguistic typology", Studies in Language 27: 61-112.

2005 A semantic approach to English grammar. Oxford: Oxford University Press.

Huddleston, Rodney

2002 "13. Comparative constructions", in: Rodney Huddleston - Geoffrey K. Pullum, 1097-1170.

Huddleston, Rodney - Geoffrey K. Pullum

2002 The Cambridge grammar of the English language. Cambridge: Cambridge University Press.

Simpson, J. A. - E. S. C. Weiner

1989 The Oxford English dictionary. (2 ${ }^{\text {nd }}$ edition.) Oxford: Oxford University Press.

Sinclair, John (founder editor-in-chief)

2001 Collins Cobuild English dictionary for advanced learners. Glasgow: HarperCollins. 